Article (refereed) - postprint

Iversen, L.L.; Winkel, A.; Baastrup-Spohr, L.; Hinke, A.B.; Alahuhta, J.; Baattrup-Pedersen, A.; Birk, S.; Brodersen, P.; Chambers, P.A.; Ecke, F.; Feldmann, T.; Gebler, D.; Heino, J.; Jespersen, T.S.; Moe, S.J.; Riis, T.; Sass, L.; Vestergaard, O.; Maberly, S.C.; Sand-Jensen, K.; Pedersen, O. 2019. Catchment properties and the photosynthetic trait composition of freshwater plant communities. Science, 366 (6467). 878-881. https://doi.org/10.1126/science.aay5945

Copyright (C) 2019 American Association for the Advancement of Science

This version available http://nora.nerc.ac.uk/id/eprint/525909/

NERC has developed NORA to enable users to access research outputs wholly or partially funded by NERC. Copyright and other rights for material on this site are retained by the rights owners. Users should read the terms and conditions of use of this material at http://nora.nerc.ac.uk/policies.html\#access

This document is the author's final manuscript version of the journal article following the peer review process. Some differences between this and the publisher's version may remain. You are advised to consult the publisher's version if you wish to cite from this article.

The definitive version is available at http://www.sciencemag.org/ 


\section{Catchment properties and the photosynthetic trait composition of}

\section{2 freshwater plant communities}

3 Short title: Catchments rule aquatic plant traits

4 One sentence summary: The geographical distribution of bicarbonate use in freshwater plants is controlled by catchment characteristics.

Author list:

8 Iversen ${ }^{*}$, L. L. ${ }^{1,2}$, Winkel ${ }^{*}$, A. ${ }^{1}$, Baastrup-Spohr ${ }^{*}$, L. ${ }^{1}$, Hinke, A. B. ${ }^{1}$, Alahuhta, J. ${ }^{3}$, Baattrup-

9 Pedersen, A. ${ }^{4}$, Birk, S. ${ }^{5}$, Brodersen, P. $^{1}$, Chambers, P. A. ${ }^{6}$, Ecke, F. ${ }^{7}$, Feldmann, T. ${ }^{8}$, Gebler, D. ${ }^{9}$,

* contributed equally

$\S$ contributed equally

\# Corresponding author (s)

1 University of Copenhagen; 2 Arizona State University; 3 University of Oulu; 4 Aarhus

University; 5 Universität Duisburg Essen; 6 Environment Canada; 7 Swedish University of Agricultural Sciences; 8 Estonian University of Life Sciences; 9 Poznán University of Life

Sciences; 10 Finnish Environment Institute; 11 Norwegian Institute for Water Research; 12

University of Illinois; 13 United Nations Environmental Program; 14 Centre for Ecology \& 
24 Unlike land plants, photosynthesis in many aquatic plants relies on bicarbonate in addition to

$25 \mathrm{CO}_{2}$ to compensate for the low diffusivity and potential depletion of $\mathrm{CO}_{2}$ in water.

Concentrations of bicarbonate and $\mathrm{CO}_{2}$ vary greatly with catchment geology. Here we

27 investigate whether there is a link between these concentrations and the frequency of freshwater plants possessing the bicarbonate use trait. We show, globally, that the frequency of plant species with this trait increases with bicarbonate concentration. Regionally however, the frequency of bicarbonate use is reduced at sites where the $\mathrm{CO}_{2}$ concentration is substantially above airequilibrium consistent with this trait being an adaptation to carbon limitation. Future anthropogenic changes of bicarbonate and $\mathrm{CO}_{2}$ concentration may alter the species composition of freshwater plant communities.

\section{MAIN TEXT}

The biogeography of terrestrial plants is influenced by climatic factors; primarily air temperature and precipitation (1). Furthermore, the distribution of biochemical traits such as the two terrestrial $\mathrm{CO}_{2}$ concentrating mechanisms, $\mathrm{C}_{4}$ photosynthesis and Crassulacean Acid Metabolism, are linked to temperature and water availability (2). Although freshwater angiosperms evolved from terrestrial ancestors (3), their growth is controlled by light, nutrients and inorganic carbon (4) rather than water, and therefore the factors influencing their biogeography is likely to be different. Inorganic carbon potentially limits photosynthesis in aquatic systems, because the diffusion of $\mathrm{CO}_{2}$ is $10^{4}$-fold lower in water than in air. 
equilibrium concentration (5). Moreover, rapid photosynthesis can reduce $\mathrm{CO}_{2}$ in water substantially below air saturation (4).

In response to carbon limitation, a few aquatic angiosperms evolved the same $\mathrm{CO}_{2}$ concentrating mechanisms found in their terrestrial ancestors, but the most frequent mechanism, found in about half of studied submerged freshwater plants, is the exploitation of bicarbonate $\left(\mathrm{HCO}_{3}{ }^{-} ;(4,6)\right)$, derived from mineral weathering of soils and rocks in the catchment. Bicarbonate is the dominant form of inorganic carbon in fresh waters when $\mathrm{pH}$ is between $\sim 6.3$ and $\sim 10.2$, and its concentration often exceeds that of $\mathrm{CO}_{2}$ by 10 - to 100 -fold (6). The ability to use bicarbonate is present in most taxonomic groups and appears to have evolved independently in cyanobacteria, eukaryotic algae and vascular aquatic plants (7). This shows the fundamental importance of bicarbonate use to plant fitness (6); increase of photosynthesis, growth and primary productivity at higher bicarbonate concentrations has been documented (8-10). However, bicarbonate use is not ubiquitous, because it involves costs as well as benefits. Costs include energy since it is an active process (11) and rates of photosynthesis at limiting concentrations of inorganic carbon are greater in $\mathrm{CO}_{2}$ users than in bicarbonate users $(5,12)$. Thus, where $\mathrm{CO}_{2}$ concentrations are substantially above air saturation, as is often the case in streams, the benefit of bicarbonate use will be reduced (13). Furthermore, obligate $\mathrm{CO}_{2}$ users can exploit alternative $\mathrm{CO}_{2}$ sources in the air, lake sediment or in the water overlying the sediment (14), allowing continued photosynthesis without the need to invest in mechanisms required for bicarbonate use.

We hypothesized that since limitation of photosynthesis by inorganic carbon supply is widespread in freshwater plants, the relative concentration of bicarbonate and $\mathrm{CO}_{2}$ at a particular 
site should determine the proportion of plants that are obligate $\mathrm{CO}_{2}$ users vs bicarbonate users. Since geochemical catchment characteristics determine bicarbonate concentration, there should be broad biogeographical patterns in the proportion of freshwater plants able to use bicarbonate while at a smaller scale, both the $\mathrm{CO}_{2}$ and bicarbonate concentrations in lakes and streams might structure the functional group composition.

To test these hypotheses, we generated a database of freshwater angiosperms and their ability to use bicarbonate as an inorganic carbon source, based on data found in the literature. These were complemented with new data we gathered on 35 species from mainly tropical regions where few prior data existed (Table S1 and (15)). The resulting 131 species represent approximately $10 \%$ of known species with a submerged life stage (16) and of these, 58 (44\%) could use bicarbonate. In order to quantify the distribution of bicarbonate users vs $\mathrm{CO}_{2}$ users, we used: i) approximately 1 million geo-referenced plant records; ii) global plant ecoregion species lists; and iii) 963 site specific plant compositions from northern hemisphere lakes and streams (Fig. S1). In each of the investigated 963 sites, plant composition was related to measured concentration of $\mathrm{CO}_{2}$ and bicarbonate. The geo-referenced plant records and ecoregion species lists were linked to local bicarbonate concentrations derived from a constructed global map of bicarbonate concentration (Fig. S2 and (15)).

In the analyzed lake and stream sites, concentrations of both bicarbonate and $\mathrm{CO}_{2}$ affected the occurrence of obligate $\mathrm{CO}_{2}$ users vs bicarbonate users, but differently within and between lakes and streams (Fig. 1, and Fig. S3). The chance of observing a bicarbonate user in lakes and streams correlated directly with concentrations of bicarbonate and $\mathrm{CO}_{2}(\Delta$ Habitat $=-0.82[-1.64$; 
$0.01]$ (mean $[95 \%$ confidence intervals]; $\Delta$ represents the difference between streams and lakes in parameter estimates at the $\log ($ odds) scale, Fig S3)), Fig. 1A). However, with increasing bicarbonate concentrations, the likelihood of observing a bicarbonate user increased in lakes, but not in streams $\left(\Delta \beta_{\text {Bicarbonate }}=-0.82[-1.10 ;-0.54]\right.$ Fig. 1B; see (15) for an explanation of $\left.\beta\right)$. Moreover, with an increase in $\mathrm{CO}_{2}$, the chance of observing a bicarbonate user decreased in both habitat types $\left(\Delta \beta_{\mathrm{CO} 2}=-0.04[-0.22 ; 0.13]\right.$, Fig. $\left.1 \mathrm{C}\right)$. The present study shows that the concentration of bicarbonate has a different effect on the proportion of bicarbonate users in lakes vs streams. Unlike in lakes, no relationship between bicarbonate availability and bicarbonate users was found in streams. This upholds our hypothesis that where concentrations of $\mathrm{CO}_{2}$ are high, the competitive advantage of using bicarbonate as a carbon source for photosynthesis will be reduced even if bicarbonate is available.

Across global plant regions (17), the shifting proportions of bicarbonate users $v s$ obligate $\mathrm{CO}_{2}$ users showed distinct spatial patterns (Fig. 2A). Compared to the overall mean, a higher proportion of bicarbonate users was observed in Africa, temperate Asia, and the northern part of North America (Fig. 2A). Globally, species utilizing bicarbonate were found in areas with higher bicarbonate concentrations (bicarbonate users $-\mathrm{CO}_{2}$ users $=0.16[0.02 ; 0.30] \mathrm{mM}$; Fig. $2 \mathrm{C}$; see Fig. 3 for a local example). The proportion of bicarbonate using species increased with bicarbonate concentrations within ecoregions $(\beta=0.14[0.05 ; 0.24]$, (mean [95\% confidence limits]), Fig. 2B). Because catchment geology and geological history shape the distribution of lakes and rivers, as well as the bicarbonate concentrations in freshwater ecosystems $(18,19)$, they are the chief determinants of plant distribution in freshwaters. $\mathrm{CO}_{2}$ concentrations are largely regulated by local $\mathrm{CO}_{2}$ supersaturated inflow (20) and ecosystem metabolism, making modeling 
114 difficult at large spatial scales $(19,21)$. Thus, future models of freshwater $\mathrm{CO}_{2}$ concentrations may improve the prediction of plant distributions even further. Although global lake and river data exist to some extent as annual means (22), given the temporal variability in $\mathrm{CO}_{2}$ concentration, the appropriate concentration would be that during the growing season at the specific site (20).

Anthropogenic changes as a consequence of deforestation, cultivation of land, application of nitrate fertilizers and reduced atmospheric acid deposition (23) are causing large scale increases in bicarbonate concentrations $(24,25)$. The observed increasing bicarbonate concentrations are expected to cause a severe impact on bicarbonate poor lakes, because higher bicarbonate concentrations will markedly change species composition (26) by allowing tall, fast growing bicarbonate users to colonize and suppress smaller species adapted to the use of $\mathrm{CO}_{2}$ alone in or near the sediment (27). There is evidence for re-establishment of species that are able to use bicarbonate, after bicarbonate has increased because of liming (28) or as a result of reduction in acid deposition (29). Moreover, systematic changes in species composition caused by changes in $\mathrm{CO}_{2}$ concentration has also been demonstrated in a river system where the proportion of $\mathrm{CO}_{2}$ users declined as $\mathrm{CO}_{2}$ decreased downstream (13). In contrast, increasing atmospheric $\mathrm{CO}_{2}$ concentrations, even if they influence dissolved $\mathrm{CO}_{2}$, will have little effect on the abundance of bicarbonate users, since increases in $\mathrm{CO}_{2}$ will be small relative to bicarbonate concentrations and will have little effect on plant photosynthesis rate (30).

Our study shows that bicarbonate use by aquatic angiosperms is widespread in fresh waters around the globe, and that the proportion of obligate $\mathrm{CO}_{2}$ users to bicarbonate users is 
significantly related to the bicarbonate concentration. Among terrestrial plants, the evolution of leaf traits and different photosynthetic pathways that enable rapid carbon assimilation and improved water economy (31) has resulted in global biogeographical patterns that are linked to variations in climate $(32,33)$. In contrast, for freshwater plants, we show that biogeographical patterns of bicarbonate use exist and that these are caused by catchment properties that determine the concentration of bicarbonate and $\mathrm{CO}_{2}$. This insight will help evaluate the repercussions of future changes in concentration of bicarbonate and $\mathrm{CO}_{2}$ on the biodiversity and ecosystem function for fresh waters.(34)

\section{REFERENCES AND NOTES}

1. M. C. Peel, B. L. Finlayson, T. A. McMahon, Updated world map of the Köppen-Geiger climate classification. Hydro. Earth Syst. Sci. Discus. 4, 439-473 (2007).

2. C. J. Still, J. A. Berry, G. J. Collatz, R. S. DeFries, Global distribution of $C_{3}$ and $C_{4}$ vegetation: carbon cycle implications. Global Biogeochem. Cycles 17, 6-1 (2003).

3. D. H. Les, N. P. Tippery, In time and with water ... the systematics of alismatid monocotyledons. Early Events Monocot Evol. 83, 118-164 (2013).

4. T. V. Madsen, S. C. Maberly, Diurnal variation in light and carbon limitation of photosynthesis by two species of submerged freshwater macrophyte with a differential ability to use bicarbonate. Freshw. Biol. 26, 175-187 (1991).

5. S. C. Maberly, T. V. Madsen, Affinity for $\mathrm{CO}_{2}$ in relation to the ability of freshwater macrophytes to use $\mathrm{HCO}_{3}{ }^{-}$. Func. Ecol. 12, 99-106 (1998).

6. S. C. Maberly, B. Gontero, Ecological imperatives for aquatic $\mathrm{CO}_{2}$-concentrating mechanisms. J. Exp. Bot. 68, 3797-3814 (2017).

7. M. Giordano, J. Beardall, J. A. Raven, $\mathrm{CO}_{2}$ concentrating mechanisms in algae: mechanisms, environmental modulation, and evolution. Annu. Rev. Plant Biol. 56, 99131 (2005).

8. K. Sand-Jensen, H. Frost-Christensen, Photosynthesis of amphibious and obligately submerged plants in $\mathrm{CO}_{2}$-rich lowland streams. Oecologia 117, 31-39 (1998).

9. M. R. Andersen, T. Kragh, K. Sand-Jensen, Extreme diel oxygen and carbon cycles in shallow vegetated lakes. Proc. R. Soc. B Biol. Sci. 284, 20171427 (2017).

10. T. V. Madsen, K. Sand-Jensen, Photosynthetic capacity, bicarbonate affinity and growth of Elodea canadensis exposed to different concentrations of inorganic carbon. Oikos 50, 176-182 (1987).

11. J. A. Raven, J. Beardall, M. Giordano, Energy costs of carbon dioxide concentrating mechanisms in aquatic organisms. Photosynth. Res. 121, 111-124 (2014). 
12. T. V. Madsen, S. C. Maberly, High internal resistance to $\mathrm{CO}_{2}$ uptake by submerged macrophytes that use $\mathrm{HCO}_{3}^{-}$: measurements in air, nitrogen and helium. Photosynth. Res. 77, 183-190 (2003).

13. S. C. Maberly, S. A. Berthelot, A. W. Stott, B. Gontero, Adaptation by macrophytes to inorganic carbon down a river with naturally variable concentrations of $\mathrm{CO}_{2}$. J. Plant. Physiol. 172, 120-127 (2015).

14. T. V. Madsen, K. Sand-Jensen, Photosynthetic carbon assimilation in aquatic macrophytes. Aquat. Bot. 41, 5-40 (1991).

15. See supplementary materials.

16. K. Murphy et al., World distribution, diversity and endemism of aquatic macrophytes. Aquat. Bot. 158, 103127 (2019).

17. R. K. Brummitt, F. Pando, S. Hollis, N. A. Brummitt, World geographical scheme for recording plant distributions. (International Working Group on Taxonomic Databases for Plant Sciences (TDWG ..., 2001).

18. R. Lauerwald, J. Hartmann, N. Moosdorf, S. Kempe, P. A. Raymond, What controls the spatial patterns of the riverine carbonate system?-A case study for North America. Chem. Geol. 337, 114-127 (2013).

19. R. Marcé et al., Carbonate weathering as a driver of $\mathrm{CO}_{2}$ supersaturation in lakes. Nat. Geosci. 8, 107-111 (2015).

20. S. C. Maberly, P. A. Barker, A. W. Stott, M. M. De Ville, Catchment productivity controls $\mathrm{CO}_{2}$ emissions from lakes. Nat. Clim. Change 3, 391 (2013).

21. L. J. Tranvik et al., Lakes and reservoirs as regulators of carbon cycling and climate. Limnol. Oceanogr. 54, 2298-2314 (2009).

22. P. A. Raymond et al., Global carbon dioxide emissions from inland waters. Nature 503, 355 (2013).

23. P. A. Raymond, S. K. Hamilton, Anthropogenic influences on riverine fluxes of dissolved inorganic carbon to the oceans. Limnol. Oceanogr. Let. 3, 143-155 (2018).

24. P. A. Raymond, N.-H. Oh, R. E. Turner, W. Broussard, Anthropogenically enhanced fluxes of water and carbon from the Mississippi River. Nature 451, 449 (2008).

25. J. L. Stoddard et al., Regional trends in aquatic recovery from acidification in North America and Europe. Nature 401, 575 (1999).

26. O. Vestergaard, K. Sand-Jensen, Alkalinity and trophic state regulate aquatic plant distribution in Danish lakes. Aquat. Bot. 67, 85-107 (2000).

27. K. Sand-Jensen, M. Sondergaard, Phytoplankton and epiphyte development and their shading effect on submerged macrophytes in lakes of different nutrient status. Internationale Revue Der Gesamten Hydrobiologie 66, 529-552 (1981).

28. T. E. Brandrud, Effects of liming on aquatic macrophytes, with emphasis on Scandinavia. Aquat. Bot. 73, 395-404 (2002).

29. D. T. Monteith et al., Biological responses to the chemical recovery of acidified fresh waters in the UK. Environ. Pollut. 137, 83-101 (2005).

30. G. Bowes, Facing the inevitable: plants and increasing atmospheric $\mathrm{CO}_{2}$. Annu. Rev. Plant Biol. 44, 309-332 (1993).

31. I. J. Wright et al., The worldwide leaf economics spectrum. Nature 428, 821-827 (2004). 
32. H. Lambers, F. S. Chapin lii, T. L. Pons, Plant physiological ecology. (Springer Science \& Business Media, 2008).

33. I. J. Wright et al., Global climatic drivers of leaf size. Science 357, 917-921 (2017).

34. L. L. Iversen. (2019).

\section{ACKNOWLEDGEMENTS}

We thank L Adamec for providing data on Oenanthe aquatica, Tropica Aquarium Plants for the generous supply of tropical aquatic plants, and K Murphy for sharing the species list of plants with a submerged life form. We acknowledge the constructive suggestions by CM Duarte, $\mathrm{H}$ Lambers and HH Bruun.

Funding: L.L.I was funded by the Carlsberg Foundation (CF17-0155 and CF18-0062). L.B.-S. was funded by the Aage V. Jensen Foundation. D.G was funded by the Polish National Agency for Academic Exchange (PPN/BEK/2018/1/00401) and K.S.-J. was funded by the Carlsberg Foundation (grant CF14-0136).

Author contributions: L.L.I., A.W., L.B-S., S.C.M., K. S.-J. and O. P. designed the study, framed the research questions, and wrote the manuscript, with input from the working group (A.B.H., J.A., A.B-P., P.B., P.A.C., F.E., T.F., J.H., T.S.J, S.J.M., T.R., L.S. and O.V.). L.L.I. analyzed the data and prepared the figures. A.B.H and O.P. performed the pH-drift experiments and together with A.W. searched the literature for bicarbonate uptake in aquatic plants. A.W., L.L.I., and L.B-S. assembled the data for the global analysis. F.E., L.B-S, L.S., S.C.M., S.J.M, J.A., and T.F. assembled the site-specific lake data and the site-specific stream data was assembled by A. B.-P., P.B., P.A.C., D.G., K.S.-J., T.R, T.S.J., and O.V., A.W., L.L.I., and L. BS. prepared the site-specific data for further analysis. 
243 Competing interests: The authors declare no competing interests.

244

245 Data availability: All R scripts and cleaned datasets used for this analysis are available at the 246 Dryad Digital Repository. 

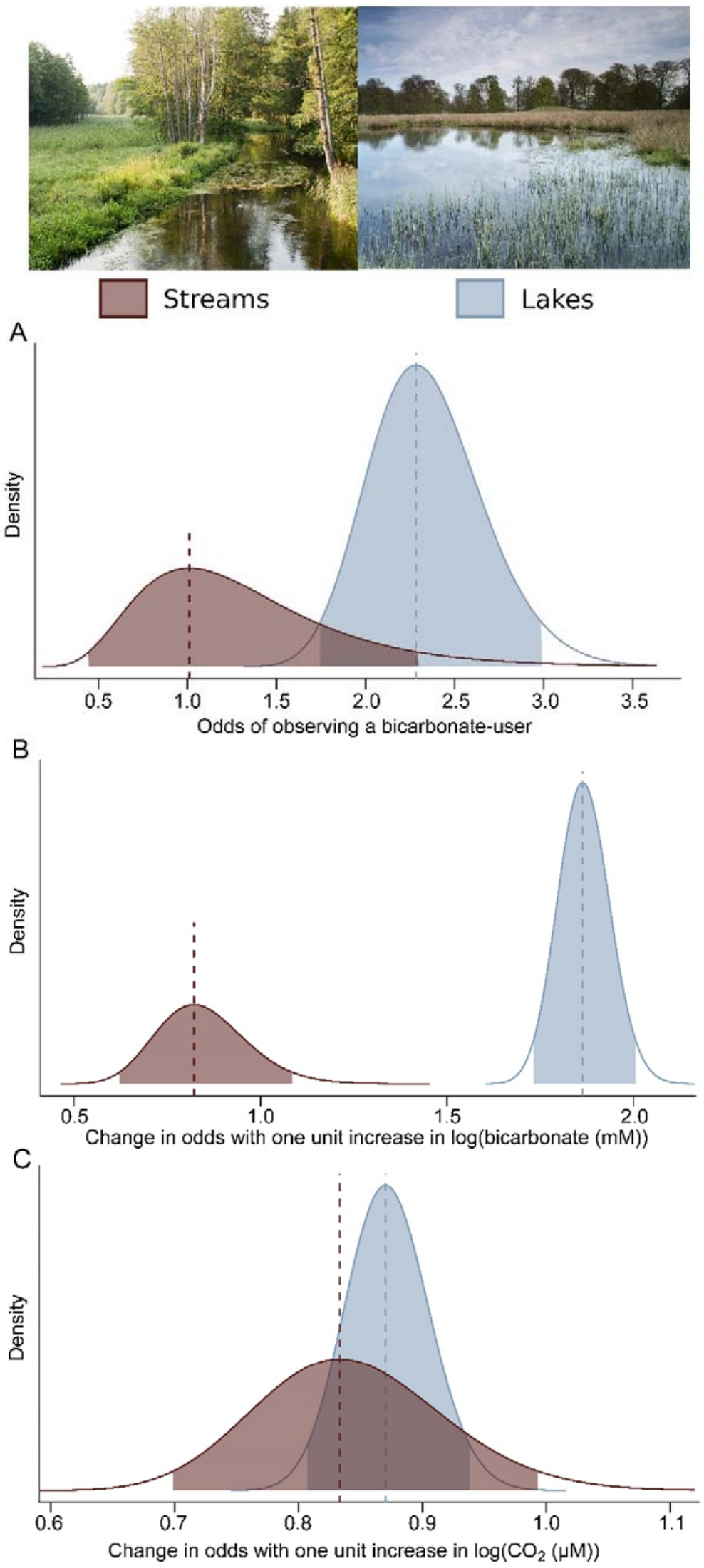

Fig. 1

\section{Bicarbonate use in submerged} freshwater plant communities.

(A) likelihood of observing a bicarbonate user vs a $\mathrm{CO}_{2}$ user in streams $(n=172$, red $)$ and lakes ( $\mathrm{n}=791$, blue); (B and C), modeled odds of observing a bicarbonate user vs a $\mathrm{CO}_{2}$ user as a function of bicarbonate $(\mathbf{B})$ and $\mathrm{CO}_{2}(\mathbf{C})$ concentrations. Values $>1$ indicate a higher likelihood (A) or increase in likelihood (B and $\mathbf{C}$ ) of observing a bicarbonate user vs a $\mathrm{CO}_{2}$ user with a one unit increase in bicarbonate $(\mathbf{B})$ and $\mathrm{CO}_{2}$ concentrations $(\mathbf{C})$. The dotted vertical lines show mean estimates and shaded areas the $95 \%$ confidence limits around the mean. 

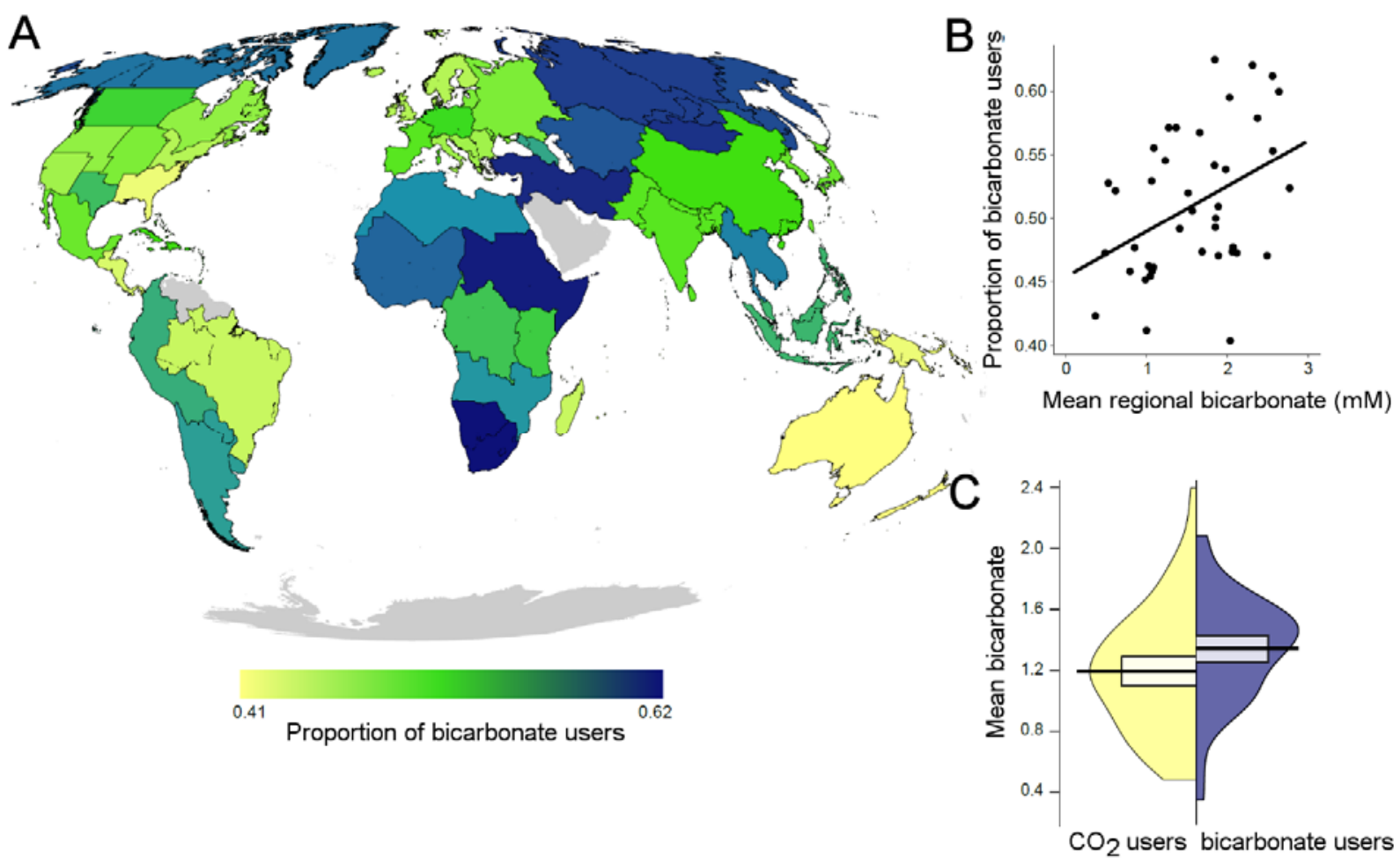

Fig. 2

\section{Global relationship between bicarbonate and the proportion of bicarbonate users in}

freshwater plants. (A) Proportion of bicarbonate using species across 52 plant ecoregions. Grey

289 areas indicate regions where information on bicarbonate use in local plants is not available. (B)

290 Relationship between mean bicarbonate concentration in plant regions and frequency of

291 bicarbonate users. The line represents the mean proportion of bicarbonate users. (C) Density

292 plots of bicarbonate preferences for bicarbonate users $(n=57)$ and obligate $\mathrm{CO}_{2}$ users $(n=72)$.

293 The central horizontal black line represents the mean and the boxes indicate the $95 \%$ confidence 294 intervals around the mean. 


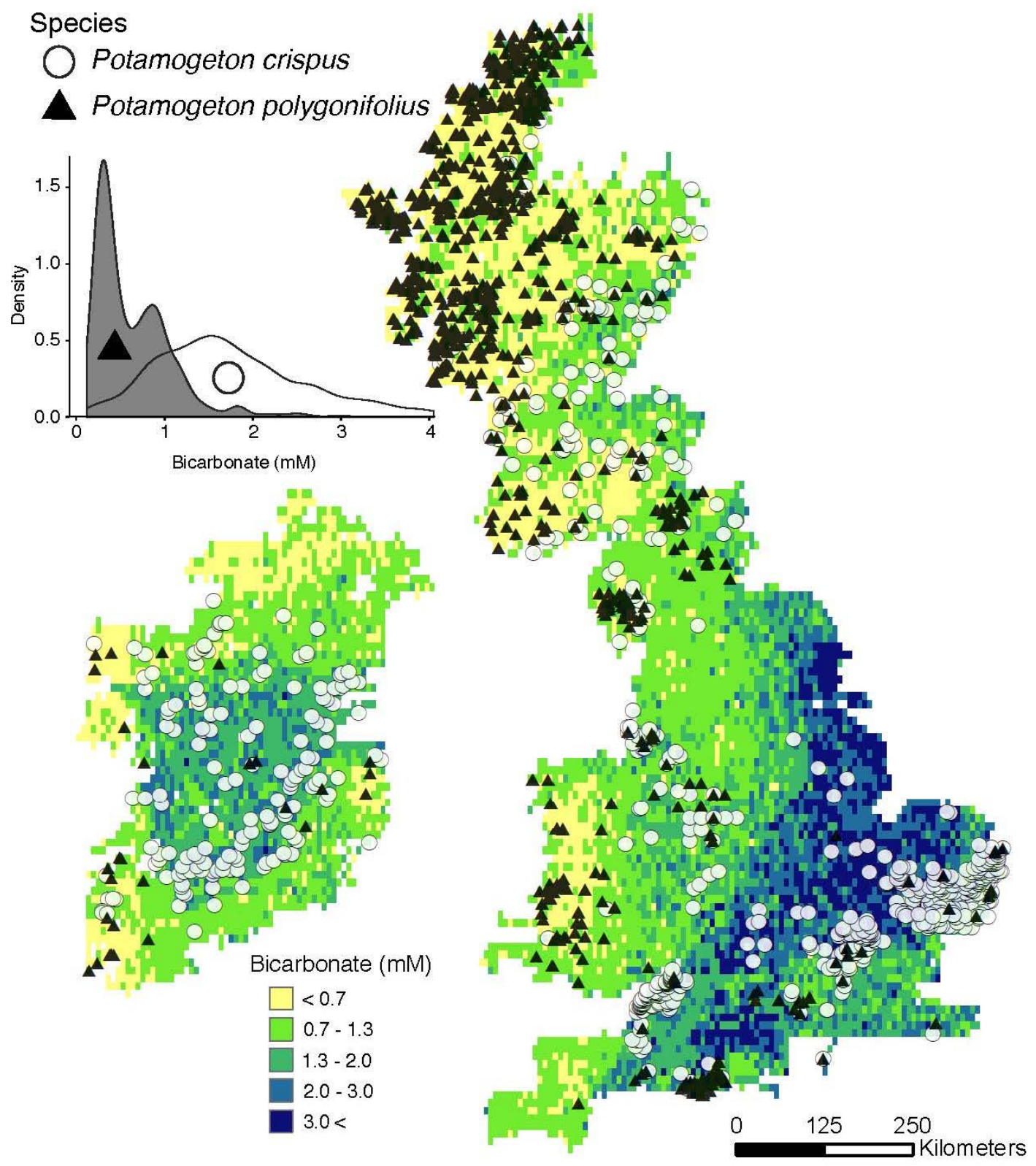

Fig. 3

300 Steep gradients in bicarbonate concentrations and spatial separation in species distribution

301 in the British Isles. Distribution of two pondweed species with contrasting bicarbonate use in

302 the British Isles. Potamogeton polygonifolius (obligate $\mathrm{CO}_{2}$ user, black triangles) is found in

303 areas with lower bicarbonate concentrations compared to Potamogeton crispus (bicarbonate user,

304 white circles). The top left insert shows the density distribution of the two species across 
305 bicarbonate concentrations. Bicarbonate concentrations are from the global bicarbonate map

306 (Fig. S2) and species data were extracted from the geo-referenced plant occurrences (15).

307

308 Supplementary Materials

309 Materials and Methods (15).

310 References (34-90).

311 Fig. S1 - Site-specific observations of bicarbonate use.

312 Fig. S2 - Global bicarbonate map.

313 Fig. S3 - The probability of observing bicarbonate use in a species at 963 study sites.

314 Fig. S4 - Overview of in situ lake bicarbonate measurements.

315 Fig. S5 - Variable importance plot of the Random Forest modelling global bicarbonate $316 \quad$ concentrations.

317 Fig. S6 - Partial dependence plots of the eight variables used to model global bicarbonate concentrations.

Fig. S7 - Histogram of taxonomic distinctness for 1000 random subsamples of a fixed number of 131 species drawn from a common species pool.

321 Table S1 - List of freshwater angiosperms and their trait of inorganic carbon use. 